\title{
Need of a Next Generation Severe Accident Code
}

\author{
Alexaandre Ezzidi Nakata ${ }^{1 *}$, Masanori Naitoh ${ }^{1}$, Chris Allison ${ }^{2}$ \\ ${ }^{I}$ The Institute of Applied Energy, 1-14-2, SY Bldg. Nishi-Shimbashi, Minato-ku, Tokyo 105-0003 JAPAN \\ ${ }^{2}$ Innovative Systems Software, L.L.C., 3585 Briar Creek Lane Ammon, Idaho 83406 USA
}

\section{ARTICLE INFO}

\section{Article history:}

Received: 21 October 2019

Received in revised form: 7 November 2019

Accepted: 8 November 2019

Keywords:

Severe accident

SAMPSON

SCDAPSIM

ASYST-ISA

Fukushima

Steam explosion

Hydrogen detonation

\begin{abstract}
A B S T R A C T
Two international severe accident benchmark problems have been performed recently by using several existing parametric severe accident codes: The Benchmark Study of the Accident at the Fukushima Daiichi Nuclear Power Plant (BSAF) and the Benchmark of the In-Vessel Melt Retention (IVMR) Analysis of a VVER-1000 Nuclear Power Plant (NPP). The BSAF project was organized by the Nuclear Power Engineering Center (NUPEC) of the Institute of Applied Energy (IAE) in Japan for the three Boiling Water Reactors (BWRs) of the Fukushima NPP. The IVMR Project was organized by the Joint Research Center (JRC) of the European Commission (EC) in Holland (Europe) for a Pressurized Water Reactor (PWR). The obtained results of both projects have shown very large discrepancies between the used severe accident codes for both reactor types BWR and PWR. Consequently, the results for a real plant analysis by these integral codes, may not be correct after the beginning of core melt. Discrepancies of results of ex-vessel phenomena in the containment between the codes are in general larger. Therefore, there is a strong need for a reliable new generation mechanistic severe accident code which can simulate severe accident scenarios from an initiating event till containment failure with better accuracy not only for existing light water reactors but also for new generation IV reactor types. SAMPSON mechanistic ex-vessel modules coupled with SCDAPSIM and a new thermal-hydraulic module ASYSTISA with particularly newly developed options for the reactor coolant system (RCS) and material properties applicable to new reactor deigns, is proposed as a best etimate new generation severe accident code for several reasons which are described in this paper.
\end{abstract}

\section{INTRODUCTION}

The development of severe accident analysis codes for Light Water Reactors (LWR) started soon after TMI-2 accident (1979) [1]. The integral codes are generally used to simulate severe accident scenarios starting from an initiating event till containment failure if crucial severe accident safety systems and/or operator actions are assumed failed.

\footnotetext{
${ }^{*}$ Corresponding author. Tel.: +81-3-6367-0814

E-mail: alex@iae.or.jp

DOI: $\underline{10.17146 / \mathrm{tdm} .2019 .21 .3 .5630}$
}

Severe accident analyses can be performed to verify or validate a reactor design and show that the consequences would be within the limits of safety requirements defined by safety authorities. They can also be performed to develop severe accident management guidelines or to conduct severe accident phenomenological probabilistic evaluations for the development of the containment event tree in the level-2 Probabilistic Risk Assessment (PRA). Several integral severe accident analysis codes have been developed in the world. Actually, MELCOR [2] and MAAP [3] which are 
most widely used codes, are lumped parameter codes which use mainly empirical correlations, many parameters derived from large-scale experiments or separate-effect tests and even user tuning parameters. These two codes may have large uncertainties in the analysis results for a real plant, they are briefly described in Section 2 below.

The objective of the present study is to show that analysis results of in-vessel core damage progression by actual integral severe accident codes are probably not reliable for real plant applications including reactor design and development of severe accident management guidelines. In order to overcome the large uncertainties in the results of actual codes, it is strongly recommended that a new generation integral severe accident code should be developed based on SCDAP/RELAP5 [5] which is considered the most accurate existing code for invessel severe accident progression and RCS thermohydraulic analysis.

\section{DESCRIPTION OF MAIN SEVERE ACCIDENT CODES}

The main severe accident analysis codes are described hereafter.

MELCOR and MAAP which are the most widely used parametric integral severe accident analysis codes in the world were developed mainly for support severe accident analyses and source term analyses of Level-2 PRA. These two codes uncertainties in the results are generally taken into account in the phenomenological probabilistic evaluations by applying probability distributions. However, these two codes do not have models for steam explosion and hydrogen detonation. Detailed descriptions of MELCOR and MAAP can be found in the user's manuals of these two codes in References [2] and [3] respectively.

SAMPSON [4] is a fully mechanistic integral severe accident analysis code which has been developed by the Nuclear Power Engineering Center (NUPEC) of the Institute of Applied Energy (IAE) with the support of the Japanese Ministry of International Trade and Industry (MITI). The main purpose of the code is to simulate all the severe accident phenomena during light water reactor severe accidents from an initiating event till containment failure and release of fission products to the environment. The modelled phenomena include: invessel steam explosion, ex-vessel steam explosion and hydrogen detonation. The code can be used also for design basis accidents as well as for Level 1 and Level 2 PRA. In addition, SAMPSON code also has specific plot programs for CFD graphical simulations that can be used for example to graphically simulate a hydrogen detonation, steam explosion or molten core relocation into the reactor cavity after reactor pressure vessel (RPV) failure.

SCDAP/RELAP5 [5] is considered as the most reliable and most accurate severe accident code to date for in-vessel accident progression of LWRs. It is the reference code which can be generally used to check the validity of in-vessel severe accident analysis results obtained by other severe accident codes. A detailed description of SCDAP/RELAP5 is provided in Reference [5].

A general comparison between the four codes is summarized in Table 1.

Table 1. Comparison of Main Severe Accident Codes

\begin{tabular}{|c|c|c|c|c|}
\hline & MAAP & MELCOR & SCDAP/RELAP5 & SAMPSON \\
\hline Developer & $\begin{array}{l}\text { Fauske \& Associates } \\
\text { Inc. for EPRI (US) }\end{array}$ & SNL-NRC & INEEL - NRC & IAE - NUPEC \\
\hline Function & $\begin{array}{l}\text { Parametric code } \\
\text { Integral analysis for } \\
\text { Level-2 PRA }\end{array}$ & $\begin{array}{l}\text { Parametric code } \\
\text { Integral analysis for } \\
\text { Level-2 PRA }\end{array}$ & $\begin{array}{l}\text { Detailed in-vessel severe } \\
\text { accident analysis, NRC \& } \\
\text { IAEA Reference code }\end{array}$ & $\begin{array}{l}\text { Detailed integral } \\
\text { severe accident } \\
\text { analysis, all } \\
\text { phenomena are } \\
\text { modeled }\end{array}$ \\
\hline Drawbacks & $\begin{array}{l}\text { No steam explosion, no } \\
\text { hydrogen detonation }\end{array}$ & $\begin{array}{l}\text { No steam explosion, } \\
\text { no hydrogen } \\
\text { detonation }\end{array}$ & No containment model & Slow calculation \\
\hline tuning parameters & Too many & many & Very few & No tuning parameters \\
\hline Simulation time & very short & $\begin{array}{l}\text { Several times real } \\
\text { time }\end{array}$ & $25 \% \sim 50 \%$ real time & $\sim 10$ times real time \\
\hline $\begin{array}{l}\text { Physical models } \\
\& \text { correlations }\end{array}$ & $\begin{array}{l}\text { Mainly empirical \& } \\
\text { parametric }\end{array}$ & $\begin{array}{l}\text { Partly empirical \& } \\
\text { parametric }\end{array}$ & Fully mechanistic models & $\begin{array}{l}\text { Fully mechanistic } \\
\text { models }\end{array}$ \\
\hline $\begin{array}{l}\text { Verification \& } \\
\text { Validation }(\mathrm{V} \& \mathrm{~V})\end{array}$ & $\begin{array}{l}\text { Mainly by separate } \\
\text { effect tests for } \\
\text { standalone models } \\
\text { International benchmark } \\
\text { and Standard Problems }\end{array}$ & $\begin{array}{l}\text { By separate effect } \\
\text { and integral effect } \\
\text { tests } \\
\text { International } \\
\text { benchmark and } \\
\text { Standard Problems }\end{array}$ & $\begin{array}{l}\text { International V\&V through } \\
\text { SCDAP Development \& } \\
\text { Training Program } \\
\text { By separate effect and } \\
\text { integral effect tests } \\
\text { International benchmark } \\
\text { and Standard Problems }\end{array}$ & $\begin{array}{l}\text { By separate effect and } \\
\text { integral effect tests } \\
\text { International } \\
\text { benchmark and } \\
\text { Standard Problems }\end{array}$ \\
\hline
\end{tabular}




\section{RESULTS OF THE BENCHMARK OF FUKUSHIMA ACCIDENT}

After Fukushima accident [6], Japan had launched in 2012 an international project called the Benchmark Study of the Accident at the Fukushima Daiichi Nuclear Power Station (BSAF) [7]. In this project severe accident analysis codes which have been developed since the accident of TMI-2, are used by participating countries to simulate Fukushima accidents.

Table 2 lists the different countries and organizations which participated in the benchmark analysis of BSAF Project with the severe accident code used by each organization.

Table 2. Participants and Used Codesin BSAF [7]

\begin{tabular}{|l|l|l|}
\hline PARTNER & CODE & COUNTRY \\
\hline CEA & Analytical study & FRANCE \\
\hline CSN/CIEMAT & MELCOR 2.1-4803 & SPAIN \\
\hline CRIEPI & MAAP 5.01 & JAPAN \\
\hline EPRI & MAAP 5.01 & U.S.A \\
\hline GRS & ATHLET-CD/COCOSYS & GERMANY \\
\hline IAE & SAMPSON-B 1.4 beta & JAPAN \\
\hline IBRAE/ROSATOM & SOCRAT/V3 & RUSSIA \\
\hline IRSN & ASTEC V2.0 rev3 p1 & FRANCE \\
\hline JAEA & THALES 2 & JAPAN \\
\hline KAERI & MELCOR 1.8.6 & SOUTH KOREA \\
\hline NRA(S/NRA/R) & MELCOR 2.1 & JAPAN \\
\hline NRC/DOE/SNL & MELCOR 2.1-5864 & U.S.A \\
\hline PSI & MELCOR 2.1_ 4203 & SWITZERLAND \\
\hline
\end{tabular}

The results of Reactor Pressure Vessel (RPV) pressure with vessel failure time and total in-vessel hydrogen generation by all used severe accident codes for Unit- 1 are presented in Figures 1 and 2 respectively.

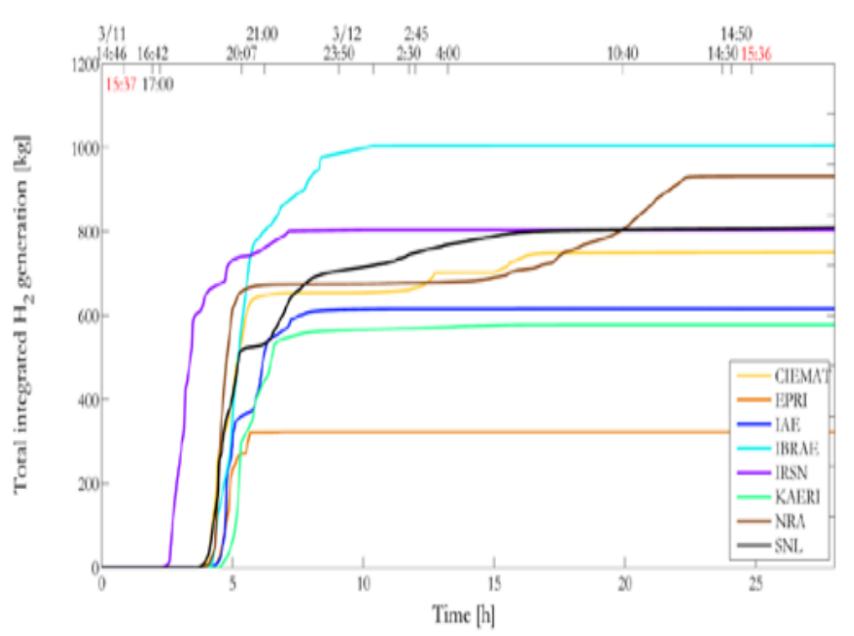

Fig. 1. Calculated Unit-1 RPV Pressure and Failure Times [7]

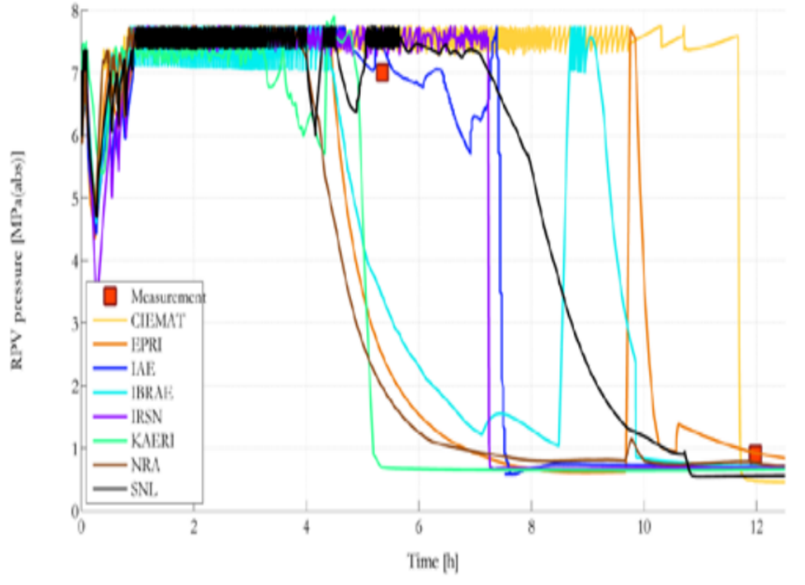

Fig. 2. Unit-1 Total Calculated In-Vessel Hydrogen Generation[7]

\section{BENCHMARK OF THE IN-VESSEL MELT RETENTION OF VVER-1000}

The Joint Research Center (JRC) of the European Commission (EC) organized an international benchmark project[8] on existing severe accident codes calculations for In Vessel Retention for VVER 1000 (IVMR-VVER1000) with the target of providing preliminary results on the feasibility of this mitigation strategy in case of severe accident for such kind of plants. The objective of the Benchmark analysis is to compare the results of different severe accident codes for the lateral maximum heat flux from the molten core debris to the lower head wall between the light metallic layer and the heavy oxide pool in lower head as shown in Figure 3.

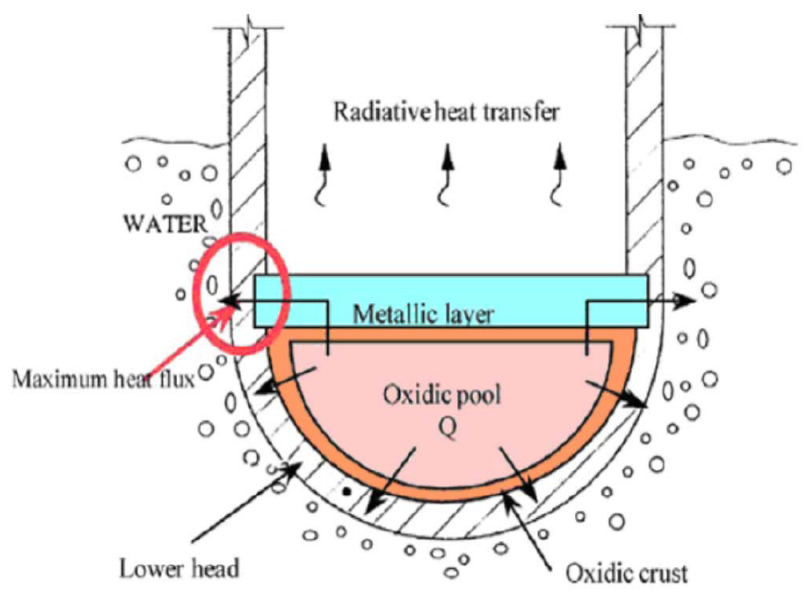

Fig. 3. Molten Debris Distribution for Evaluation of Focusing Effect [8] 
Table 3 lists the different organizations which participated in the benchmark analysis of the IVMR-VVER1000 Project with the severe accident code used by each organization.

Table 3. Participants and Codes Used in the IVMR Benchmark Project [8]

\begin{tabular}{|l|c|c|c|c|c|c|}
\hline & \multicolumn{7}{|c|}{ Mechanistic Codes } \\
\cline { 2 - 7 } & $\begin{array}{c}\text { ASTEC } \\
\text { integral }\end{array}$ & $\begin{array}{c}\text { ASTEC } \\
\text { stand- } \\
\text { alone }\end{array}$ & SOCRAT & MAAP & PROCOR & MELCOR \\
\hline EDF & & & & $x$ & & \\
\hline CEA & & & & & $x$ & \\
\hline UJV & & & & & & $x$ \\
\hline KI & & $\mathrm{x}$ & $\mathrm{x}$ & & & \\
\hline INRNE & & $\mathrm{x}$ & & & & \\
\hline TUS & & $\mathrm{x}$ & & & & \\
\hline JRC & & $\mathrm{x}$ & & & & \\
\hline IVS & $\mathrm{x}$ & $\mathrm{x}$ & & & & \\
\hline VTT & & $\mathrm{x}$ & & & & \\
\hline
\end{tabular}

- UJV Rez ( CEZ Republic), - IRSN (France), • CEA (France), $\bullet$ EdF (France), • Areva (France), • KI Moscow (The Russian Federation), - INRNE (Bulgaria), - TUS (Bulgaria), - Kozloduy NPP (Bulgaria), • IPP (Ukraine), - IVS (Slovakia), • USTUTT (Germany), • VTT (Finland), • JRC-IET (EC)

The results of maximum lateral heat flux to the lower head wall versus elevation and versus time calculated by different severe accident analysis code are presented in Figures 4 and 5 respectively.

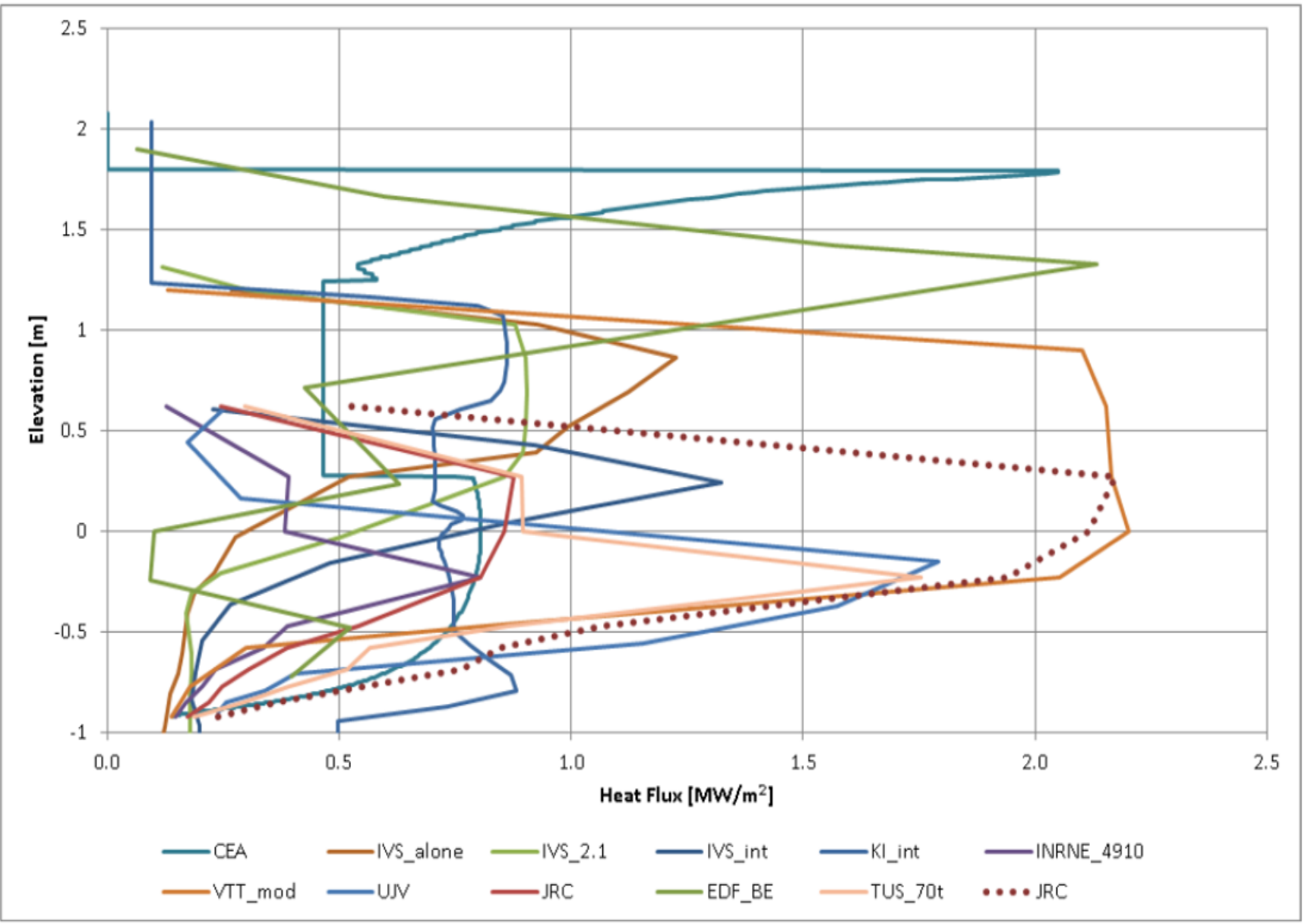

Fig. 4. Calculated Maximum Lateral Heat Flux Versus Elevation [8] 


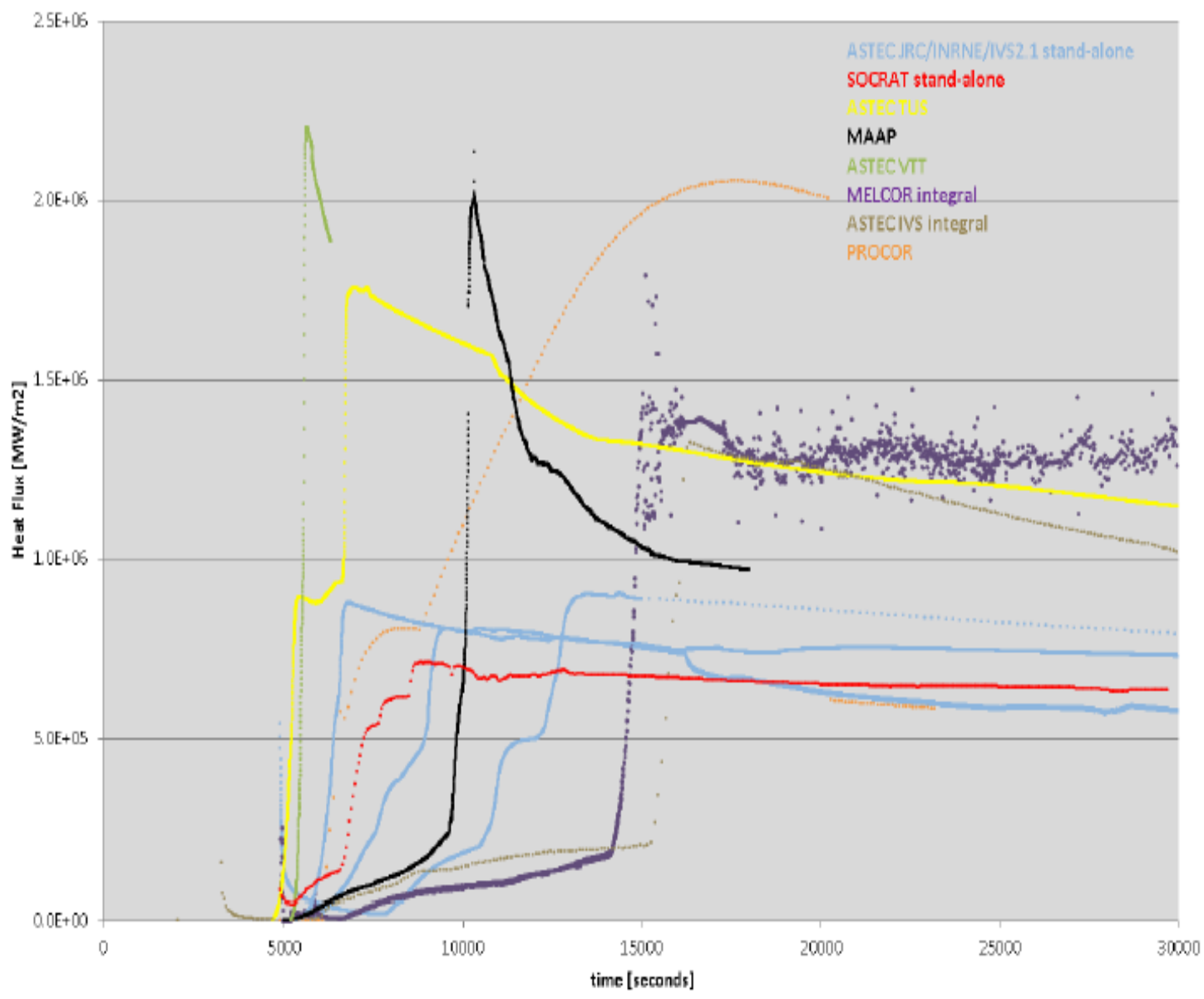

Fig. 5. Calculated Maximum Lateral Heat Flux Versus Time [8]

\section{INCONSISTENCIES IN RESULTS OF ACTUAL SEVERE ACCIDENT CODES}

Concerning the BSAF international benchmark problem [7], the common-case analyses were not altogether successful in normalizing comparative results of the various severe accident codes. This is despite that even when the common boundary conditions were implemented by all the codes, some codes led to physically unrealistic conditions causing code execution failures or other results that were not consistent with data of known accident progression trends. Indeed, even when the codes have used a same input with same boundary conditions and initial conditions, or after each participant organization used its own judgment to come up with best estimate boundary conditions to reperform the analysis, the dicrepancies in the reults between the code became larger.

Regarding the IVMR-VVER1000 international problem [8], the lower head model for the same reactor VVER-1000 with exactly the same boundary conditions and initial conditions was used for the analyses by the different severe accident codes. However, the obtained results for the maximum lateral heat flux to the lower head wall, which is the main parameter used for the calculation of the time to rupture of the vessel lower head by all the severe accident codes, show very large differences between the codes.

The results of both international benchmark problems, BSAF and IVMR-VVER1000, presented in Sections 3 and 4 respectively, show very large differences in the most important two parameters of in-vessel severe accident progression: namely the time of vessel failure and the total hydrogen generation for BSAF project. This is for the main integral severe accident codes which are widely used around the world (MAAP, MELCOR, SAMPSON). The other codes which have limited use and users may not be considered as internationally validated or they are still at early phase of the development. SCDAP/RELAP5 does not have containment models and ex-vessel models because this code is limited to in-vessel severe accident progression and RCS thermal hydraulic analyses till RPV failure. 
The main reason for these differences in the results between the main codes, MAAP and MELCOR, is important model differences during in-vessel core degradation phase starting from the core. For example, the melting temperature in MAAP and MELCOR codes is wrongly assumed as an input parameter that can be adjusted for the desired results. The melting temperature is a physical experimental data that its value cannot be modified by the users. On the other hand, MAAP code does not consider the radial relocation of particulate or molten material during the core degradation. It assumes that downward motion of core debris is the primary mode of relocation, this is contrary to what had been observed in TMI-2 accident [1].

Furthermore, tuning parameters used in the parametric codes, MAAP and MELCOR, usually are tuned with default values determined through validation studies which have been performed mainly by using stand-alone models to simulate separate effect tests [10] or by some integral effect tests [11] which have been performed under conditions different from real plant severe accident conditions. Therefore, the default values of these tuning parameters are unlikely to apply to a severe accident analysis of a real plant and the results under these conditions probably cannot be considered a reliable.

\section{DEVELOPMENT OF A NEXT GENERATION SEVERE ACCIDENT CODE}

SAMPSON [4] is an integral severe accident analysis code which has been developed by the Nuclear Power Engineering Center (NUPEC) with the support of the Japanese Ministry of International Trade and Industry. The main purpose of the code is to simulate all the severe accident phenomena during light water reactor severe accidents from an initiating event till containment failure and release of fission products to the environment. The modelled phenomena include: molten core concrete interaction, fission product transport, steam explosion and hydrogen detonation. The code can be used also for design basis accidents analyses as well as for Level 1 and Level 2 PRA [9].

The actual standard version of SAMPSON code is composed of 11 inter-connected analysis modules and two modules for off-line use (DDOC and HYNA). The Modular structure of the code is shown in Figure 6. Depending on the plant status and the analyzed severe accident scenario, a suitable set of modules can be selected through the Analysis Control Module (ACM). The code has been validated by a wide range of simulation analyses for both separate-effect tests and integraleffect tests mainly through International Standard Problems (ISPs) [10], [11].

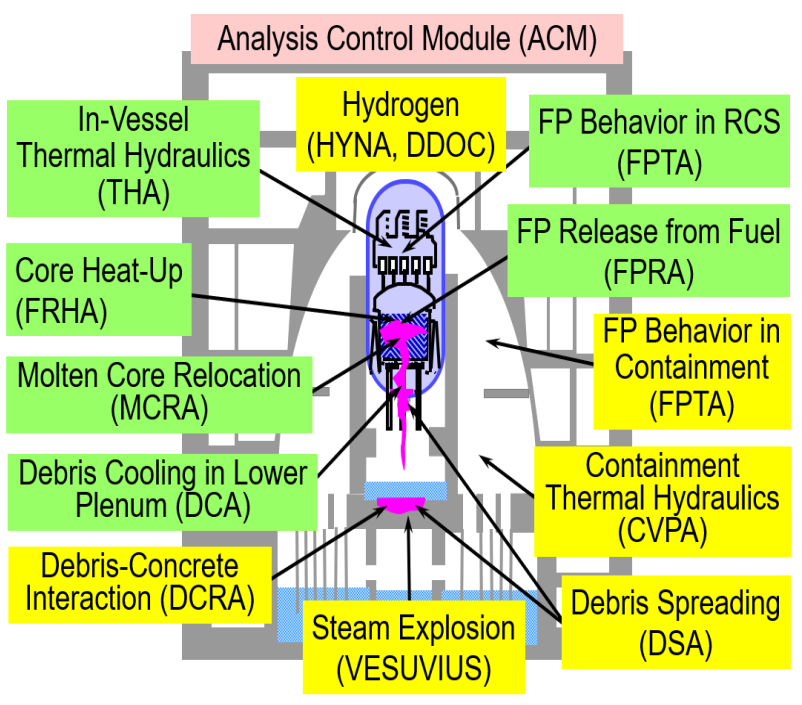

Fig. 6. Structure of SAMPSON Code ( $\Rightarrow$ :in-vessel, : ex-vessel)

As indicated in Table 1, the only disadvantage of using SAMPSON code is that the calculation time is very long ( $\sim 10$ times real time). The main reason for this slow calculation is that the in-vessel accident progression involves 5 different modules which run parallelly and separately: THA, FRHA, FPRA, MCRA and DCA. In order to overcome this problem, the idea which was selected among others, in a first step, is to replace these 5 modules, THA, FRHA, FPRA, MCRA and DCA, by the reference code SCDAP/RELAP5 [5] which is faster than real time and which is considered the most accurate severe accident code to date for in-vessel accident progression till RPV failure.

On the other hand, in the second step, it was decided to extend SAMPSON code capabilities to be able to simulate severe accident scenarios, not only for LWRs, but also for next generation reactors (Gen-IV). Therefore, an historical cooperation agreement was signed in 2019 between Nuclear Power Enginering Center in Japan and Innovative Systems Software in the US which owns the commercial version SCDAPSIM [12] of SCDAP to jointly develop a new thermal-hydraulic module [14] to replace RELAP5 [13] for which the use was recently restricted by the US Department of Energy (DOE) [15], and to replace SAMPSON module THA.

The new thermal-hydraulic module [14] which is named: Adaptive SYStem Thermal-hydraulics Integral Simulation \& Analysis "ASYST-ISA" is 
then being jointly developed to calculate the behavior of RCS, containment, and auxiliary buildings. The new module incorporates advanced multi-D, multi-fluid hydro models developed for both SAMPSON [4] and SCDAPSIM/MOD4 [12] as well as models for new reactors. These models are summarized as follows:

- Advanced water properties developed for Super-Critical Water Reactor (SCWR) and Heavy Pressurized Water Reactor (HPWR),

- Molten salt/metals,

- Single phase non-condensable gases,

- Specific models for Small Modular Reactor (SMR), High Temperature Gas Cooled Reactor (HTGR), Pebble bed Reactor (PBR) and Molten Salt Reactor (MSR).

- Subchannel analysis capability

Figure 7, shows the structure of the new SAMPSON code with SCDAPSIM Mod 4 module and ASYST-ISA module.

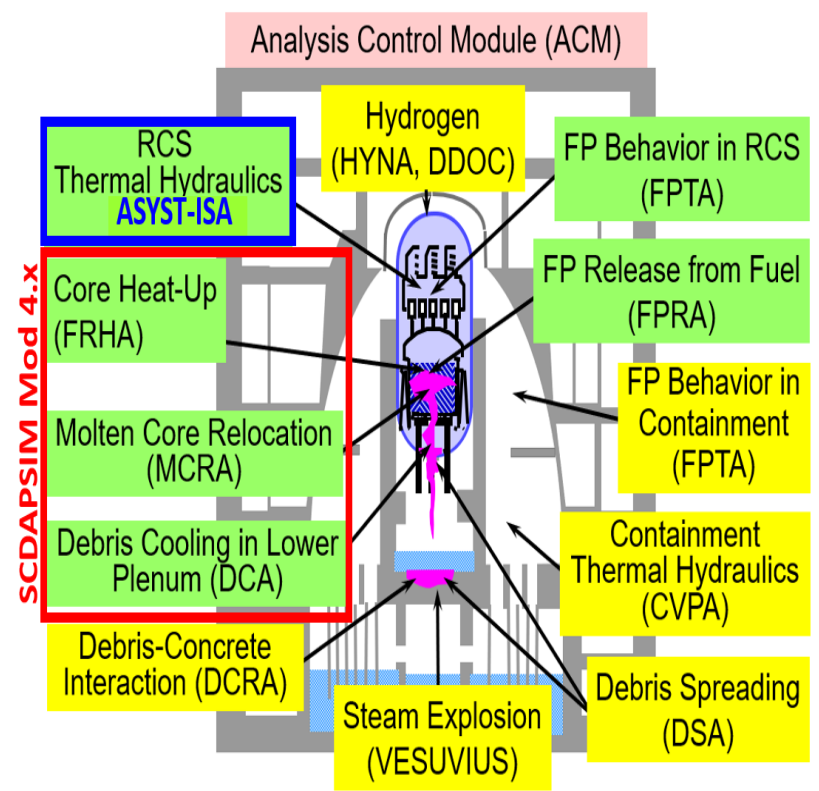

Fig. 7. Structure of the New SAMPSON with SCDAP and ASYST-ISA Modules

The ASYST reactor-specific modeling options include modules describing the behavior of (a) the core/fuel assembly structures, (b) late phase debris/melt relocation, (c) the containment including melt spreading and molten core-concrete interactions, and (d) fission product release and transport. The core/fuel assembly behavior module uses derivatives of SCDAPSIM models and correlations while the late phase debris/melt relocation module uses a combination of SCDAPSIM (2D based) models and SAMPSON MCRA, DCA, DSA (3D-based) models. The fission product release and transport module uses combinations of models from SCDAPSIM and SAMPSON. The core-concrete interaction module uses a SCDAPSIM-based porous media model in combination with SAMPSON Debris-Concrete Interaction (DCRA) models and correlations. The reactor vessel, reactor coolant system and containment thermal hydraulic behavior is described by ASYST-THA in combination with the SAMPSON hydrogen combustion, hydrogen detonation and steam explosion modules, HYNA, DDOC and VESUVIUS, respectively.

\section{CONCLUSION}

Results for important severe accident parameters obtained in two international severe accident benchmark problems, BSAF for a BWR severe accident and IVMR-VVWE1000 for a PWR severe accident, by using actual severe accident integral codes (MAAP, MELCOR, ASTEC, SAMPSON...) are investigated. The obtained results of both projects have shown very large differences between the widely used severe accident codes for both reactor types BWR and PWR. Consequently, the results for a real plant analysis by these integral codes, cannot be considered reliable and using these results for the development of criteria for Severe Accident Management Guidelines (SAMG) may not be appropriate. These parametric severe accident codes have been developed mainly to be used for Level-2 PRA where large uncertainties are taken into account in probability distributions for the uncertain parameters.

Therefore, a new generation fully mechanistic severe accident code is being developed to simulate severe accident scenarios with best accuracy, based on the NRC's reference code SCDAP/RELAP5 (the ISS's SCDAPSIM/RELAP5) and the IAE/NUPEC's SAMPSON ex-vessel modules. The new code will also incorporate a new thermalhydraulic module ASYST-ISA with particularly newly developed options for the reactor coolant system and material properties applicable to new reactor designs of Gen. IV.

\section{REFERENCES}

1. J. R. Wolf, et al., "TMI-2 Vessel Investigation Project Integration Report", NUREG/CR6197, March 1994. 
2. Gauntt, R.O., Cash, J.E., Cole, R.K. et al., MELCOR Computer Code Manuals, Sandia National Laboratories.

3. EPRI, Modular Accident Analysis Program 5 (MAAP5) Applications Guidance, 2015.

4. M. Naitoh et al., "Development of severe accident analysis code SAMPSON in IMPACT project”, J. Nucl. Sci. Technol., 36, 11, 1999, 1076.

5. SCDAP/RELAP5, NUREG/CR-6150, Vol. 1, Rev. 2 INEL-96/0422.

6. World Nuclear Association, "Fukushima Accident 2011," September 2014, http://www.world-nuclear.org/info/Safety-andSecurity/Safety-of-Plants/FukushimaAccident-2011. Radioactivity units converted from 940 petabecquerels of Iodine-131 equivalent.

7. OECD/NEA, "Benchmark Study of the Accident at the Fukushima Daiichi Nuclear Power Plant (BSAF Project)", Nuclear Regulation, NEA/CSNI/R(2015)18, February 2016.

8. Marco SANGIORGI, Alexandre Ezzidi et al.," In-Vessel Melt Retention (IVMR) Analysis of a VVER-1000 NPP”, European Commission, JRC Technical Reports, 2016.

9. A. Ezzidi Nakata et al., "Sampson Analysis of PWR Induced Steam Generator Tube Rupture", NTHAS11: The Eleventh KoreaJapan Symposium on Nuclear Thermal Hydraulics and Safety, Busan, Korea, Paper No. N11O0173, November 18-21, 2018.
10. Takashi Ikeda et al., "Analysis of International Standard Problem No. 45, QUENCH06 Test at FZK by Detailed Severe Accident Code, IMPACT/SAMPSON", Journal of NUCLEAR SCIENCE and TECHNOLOGY, Vol. 40, No. 4, p. 246-255 (April 2003).

11. Takashi Ikeda et al., "Analysis of Core Degradation and Fission Products Release in Phebus FPT1 Test at IRSN by Detailed Severe Accident Analysis Code, IMPACT/SAMPSON", Journal of NUCLEAR SCIENCE and TECHNOLOGY, Vol. 40, No. 8, p. 591-603 (August 2003).

12. C.M. Allison, R.J. Wagner, L.J. Siefken, J.K. Hohorst, "The Development of RELAP/SCDAPSIM/MOD4.0 for Reactor System Analysis and Simulation", Proceedings of the 7th International Conference on Nuclear Option in countries with Small and Medium Electricity Grids, 25-29 May 2008, Dubrovnik (Croatia), Paper No. S-05.01.

13. US-NRC RELAP5/MOD3.3 Code Manual, Volumes I to VIII. NUREG/CR-5535/Rev 1 2001.

14. C.M. Allison, J.K. Hohorst, A. Ezzidi, and M. Naitoh, "Preliminary Assessment of the new ASYST - ISA Integral Analysis Code Using Selected Integral Thermal Hydraulic - Fuel Assembly Experiments", 25th International QUENCH-Workshop, KIT, Germany, Oct. 2224, 2019.

15. Title 10 CFR, Part 810 - Assistance to Foreign Atomic Energy Activities, US-NRC. 